\title{
Ovenbird (Seiurus aurocapilla) Territory Placement Near Seismic Lines is Influenced by Forest Regeneration and Conspecific Density
}

\section{Le positionnement des territoires de la Paruline couronnée (Seiurus aurocapilla) près des lignes sismiques est influencé par la régénération forestière et la densité des conspécifiques}

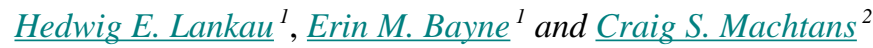

\begin{abstract}
The boreal forest of western Canada is being dissected by seismic lines used for oil and gas exploration. The vast amount of edge being created is leading to concerns that core habitat will be reduced for forest interior species for extended periods of time. The Ovenbird (Seiurus aurocapilla) is a boreal songbird known to be sensitive to newly created seismic lines because it does not include newly cut lines within its territory. We examined multiple hypotheses to explain potential mechanisms causing this behavior by mapping Ovenbird territories near lines with varying states of vegetation regeneration. The best model to explain line exclusion behavior included the number of neighboring conspecifics, the amount of bare ground, leaf-litter depth, and canopy closure. Ovenbirds exclude recently cut seismic lines from their territories because of lack of protective cover (lower tree and shrub cover) and because of reduced food resources due to large areas of bare ground. Food reduction and perceived predation risk effects seem to be mitigated once leaf litter (depth and extent of cover) and woody vegetation cover are restored to forest interior levels. However, as conspecific density increases, lines are more likely to be used as landmarks to demarcate territorial boundaries, even when woody vegetation cover and leaf litter are restored. This behavior can reduce territory density near seismic lines by changing the spatial distribution of territories. Landmark effects are longer lasting than the effects from reduced food or perceived predation risk because canopy height and tree density take $>40$ years to recover to forest interior levels. Mitigation of seismic line impacts on Ovenbirds should focus on restoring forest cover as quickly as possible after line cutting.
\end{abstract}

RÉSUMÉ. La forêt boréale de l'ouest du Canada subit un découpage par les lignes sismiques effectuées dans le cadre de l'exploration pétrolière et gazière. La grande quantité de bordures ainsi créées soulève des préoccupations quant à l'intégrité des milieux pour les espèces forestières de massifs continus, et ce, pour de longues périodes. La Paruline couronnée (Seiurus aurocapilla) est un passereau boréal reconnu pour sa sensibilité aux lignes sismiques récemment créées parce qu'elle exclut les bandes nouvellement coupées de son territoire. Afin d'examiner les nombreuses hypothèses pouvant expliquer les mécanismes possibles derrière ce comportement, nous avons cartographié les territoires de parulines situés près de lignes, selon différents stades de régénération de la végétation. Le modèle qui explique le mieux le comportement d'exclusion des lignes inclut le nombre de conspécifiques voisins, la superficie de sol nu, la profondeur de la litière forestière et la superficie du couvert forestier. Les parulines excluent les lignes sismiques récemment coupées de leur territoire en raison du manque de couvert de protection (couvert arbustif et en petits arbres) et des ressources alimentaires réduites attribuables aux grandes superficies de sol nu. La faible quantité de ressources alimentaires et les risques perçus de prédation semblent être compensés une fois que la litière forestière (profondeur et étendue) et le couvert forestier ont ratteint les niveaux des massifs continus de forêts. Toutefois, à mesure que la densité de conspécifiques augmente, les lignes sismiques servent vraisemblablement de repères pour démarquer les limites des territoires, même lorsque le couvert forestier et la litière ont été restaurés. En modifiant la répartition spatiale des territoires, ce comportement peut amener une réduction de la densité de territoires près des lignes sismiques. L'effet de repère dure plus longtemps que les effets imputables aux ressources alimentaires réduites et au risque perçu de prédation étant donné que la hauteur et la densité des arbres prennent plus de 40 ans à ratteindre les niveaux des massifs continus de forêts. Les mesures destinées à atténuer l'impact des lignes sismiques devraient viser à restaurer le couvert forestier dès que possible.

Key Words: bird territory mapping; boreal forest; Canada; landmarks; Ovenbird (Seiurus aurocapilla); regeneration; seismic lines

${ }^{1}$ Integrated Landscape Management Group, University of Alberta, ${ }^{2}$ Environment Canada
Sponsored by the Society of Canadian Ornithologists and Bird Studies Canada Parrainée par la Société des ornithologistes du Canada et Etudes d'oiseaux Canada

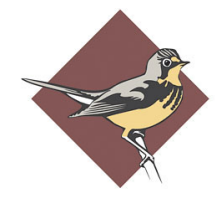

BIRD STUDIES CANADA 


\section{INTRODUCTION}

The boreal forest that is underlain by the western Canadian sedimentary basin is continuing to be dissected by oil and gas exploration. Dissection is the stage along a fragmentation continuum when initial access into an ecosystem occurs (Hunter 1999) and is mainly caused by linear features. Accumulation of oil and gas features such as roads, pipelines, and seismic lines is leading to concerns that interior habitat is being reduced for forest interior species due to the amount of edge from these disturbances (Schneider 2002). Seismic lines are the dominant source of dissection caused by the energy sector (Schneider 2002, Lee and Boutin 2006). Historically, seismic lines were 5- to 8-m strips that extended for tens to hundreds of kilometers and were cleared of all forest cover to survey for oil and gas reserves. Currently, seismic lines can be $<2 \mathrm{~m}$ wide in certain circumstances but typically are 3 to 5-m wide (Schneider 2002). After exploration, seismic lines are typically left to regenerate naturally. Regeneration can be poor because of continued human activity on the lines (e.g., all-terrain vehicle access) and poor growing conditions caused by altered light regimes, soil compaction, and/or soil moisture changes (Lee and Boutin 2006). The perception that seismic lines are not recovering and are causing long-term fragmentation effects on a variety of wildlife species has led to calls for limits on seismic line density (Dehcho Land Use Planning Committee 2006, Kennet 2006).

Current thresholds for seismic line density do not distinguish among different types or ages of seismic lines (Environment Canada 2011). Lines are visible on the landscape for long periods of time (Lee and Boutin 2006) but impacts on biodiversity are not necessarily related to visibility. To impose limits on the number of seismic lines deemed acceptable for biodiversity requires an understanding of which types and ages of lines create fragmentation effects and for how long these effects last. We argue that using wildlife as management indicators of seismic line impacts is one tool for deciding whether seismic lines have a functional impact and when that impact has been mitigated.

The Ovenbird (Seiurus aurocapilla) is the only boreal songbird whose response to seismic lines has been studied (Bayne et al. 2005a, 2005b; Machtans 2006), and its known sensitivity to lines makes it a potential management indicator for determining when a seismic line has recovered (Lindenmayer et al. 2000). In high-density populations, Ovenbirds defend territories directly up to the edge of seismic lines (conventional 8-m width) but do not include the lines within their territories (Bayne et al. 2005b). In lower-density populations, Ovenbirds place their territories away from seismic lines the year immediately after lines were cut (Machtans 2006). The end result of this behavior is fewer Ovenbirds in areas with high seismic line density (Bayne et al. 2005b, Machtans 2006). This behavior does not occur when lines are 3-m wide or less, suggesting industry best practices are an effective mitigation option (Bayne et al. 2005a). However, narrowing line width is not an option in all exploration events. An alternative mitigation strategy is to actively restore vegetation on wider seismic lines. No information exists on the composition and structure of vegetation on seismic lines required to reduce dissection effects for birds. Developing mitigation strategies for seismic lines requires an understanding of why species like the Ovenbird do not include wide seismic lines within their territories and/or why they avoid seismic line edges.

We suggest three mechanisms to explain why Ovenbirds exclude seismic lines from their territories. The food abundance hypothesis suggests Ovenbirds exclude lines from their territories because the lines are poor foraging habitat. Reduction in leaf-litter quality due to forest edge microclimate is a suggested cause for Ovenbird sensitivity to road edges and forest patch size (Burke and Nol 1998, Ortega and Capen 1999). Leaf-litter depth and vegetation structure are shown to be correlated with abundance of invertebrate prey (Smith and Shugart 1987, Burke and Nol 1998, Haskell 2000, VanWilgenburg 2001), and recently cut lines with reduced leaf-litter depth and cover may have lower food resources. Similarly, seismic lines may have lower litter depth (and lower food abundance) because leaf litter is disturbed or removed during line clearing. If food abundance is the main factor influencing line exclusion, recovery of leaf-litter depth to that of forest interior values should cause line exclusion behavior to disappear.

The protective cover hypothesis suggests that seismic lines are not included within territories because they represent a risky environment with insufficient shrub cover to conceal nests or to protect foraging adults and juveniles (Rodriguez et al. 2001, Walther and Gosler 2001, Eggers et al. 2008). Many species of mammals and raptors use linear features for movement and hunting (Latham et al. 2011, Tigner 2012), and Ovenbirds may be exposed to higher predation risk on recently cut lines as they cross from one side to the other or attempt to forage on the line. If lines are avoided because they are perceived as having greater risk, then regeneration of overhead cover should cause seismic line exclusion to disappear.

Finally Ovenbirds may live up to the edge of but not include seismic lines in their territories because lines act as landmarks (Bayne et al. 2005a). Landmarks are habitat features that reduce conflict between territory holders by providing a visible marker that is used to define territory boundaries (MestertonGibbons and Adams 2003). Anecdotal evidence suggests that birds in open habitats use landscape features such as ridges and streams as boundaries (Errington 1930, Reid and Weatherhead 1988) and that forest birds may use vegetation features (St. Louis et al. 2004). Seismic lines create a visible break in continuous forest canopy similar to streams or ridges. According to the landmark hypothesis, if Ovenbirds use seismic lines as landmarks, individuals would be more likely to exclude seismic lines from their territories in areas where 
there are greater numbers of conspecifics because such individuals are more likely to have a neighbor on the other side of the line. In addition, individuals should spend less time defending the portion of their territory adjacent to seismic lines than the areas surrounded by uniform forest because of reduced defense costs (Eason et al. 1999). Our objective was to examine how Ovenbirds behave near seismic lines with different levels of vegetation recovery and to test which aspect of vegetation structure best explains their behavior. By understanding the mechanisms causing Ovenbirds to exclude seismic lines, the energy sector will be better able to mitigate their effects and have a better understanding of how long seismic lines last based on their effects on bird territory behavior.

\section{METHODS}

\section{Study site}

Our study area was near Fort Liard, Northwest Territories, Canada. Mean annual precipitation is 350 to $500 \mathrm{~mm}$ and mean seasonal temperatures range from $-20^{\circ} \mathrm{C}$ in the winter to $14^{\circ}$ $\mathrm{C}$ in the summer. Forest types include black spruce (Picea marianna) bogs, white spruce (Picea glauca), trembling aspen (Populus tremuloides), paper birch (Betula papyrifera), and mixedwood stands. There is one primary road in the area. Oil and gas exploration has happened in periodic bursts over time and there are currently no producing wells. The low amount of human use of seismic lines in this region means that many lines have started to regenerate naturally, unlike seismic lines in other areas of western Canada (Lee and Boutin 2006).

\section{Seismic line selection}

We selected 25 seismic lines that ran through deciduous habitat suitable for Ovenbirds (trembling aspen (Populus tremuloides) or paper birch (Betula papyrifera) dominated forests). Lines were selected to get a range of variation in vegetation regrowth on the line. Vegetation cover on lines ranged from bare ground to tall shrubs and saplings that reached close to the canopy height of the surrounding forest. The oldest lines were cut 40 years ago. The bare lines were generally used as winter roads or local all-terrain vehicle (for example, snowmobile) access routes. Four of the more revegetated lines had active human trails that were 2 to $3-\mathrm{m}$ wide down the center of much taller online vegetation. All lines had some gap in the canopy, giving them a functional width of 5 to $12 \mathrm{~m}$ at forest canopy height. We classified line segments adjacent to Ovenbird territories based on vegetation height as: bare (no woody regrowth), open (woody shrub regrowth up to $2 \mathrm{~m}$ ), medium (shrubs and saplings up to $6 \mathrm{~m}$ ), or closed (tall shrubs, saplings, and trees $>6 \mathrm{~m}$ in height).

\section{Territory mapping}

We color banded (by means of Environment Canada Permit No. $10277 \mathrm{U}$ ) and mapped the territories of male Ovenbirds using methods similar to Barg et al. (2004). Birds were tracked between 4:00 AM to 12:00PM when they were actively defending territories. Each individual was tracked two to three times for $\sim 3 \mathrm{~h} /$ day from its arrival on territory (last week of May) to the end of June. Individual singing locations of male birds were marked with flagging tape and then mapped using a handheld Trimble Nomad GPS data recorder. At each singing location we recorded the amount of time a male spent there and whether he was countersinging with a neighbor. We took a compass bearing and estimated the distance to each neighbor that the focal bird countersang with. The number of Ovenbird territories directly adjacent to the focal territory was also estimated to get a measure of local density of birds (the number of immediate neighbors for each focal bird). Birds were counted as neighbors if they countersang with the individual we were tracking and if their territory edge was within $100 \mathrm{~m}$ (approximate diameter of an Ovenbird territory) of the bird we tracked. Territories were located in patches of deciduous forest (within a matrix of other forest types) that were bisected by one or two seismic lines. Each patch of forest sampled was at least $1 \mathrm{~km}$ apart. We mapped 1 to 3 focal territories per patch depending on the size of the patch. We ensured that we distinguished these individuals consistently by using color bands (when visible in dense foliage), noting unique song types, and mapping territories simultaneously with multiple observers. We compared singing locations and countersinging events between tracking sessions to ensure that we had the same bird. We did not map the territories of birds that were directly adjacent to each other across the seismic line because their responses to the line would not be independent. We also eliminated any individuals whose territory boundary was found to be more than $50 \mathrm{~m}$ from a line and/or where we detected another bird singing between the focal territory and the seismic line at some point during the breeding season. The singing locations of each male Ovenbird were used to derive $100 \%$ minimum convex polygons.

\section{Simulation}

We created a simulation model in a GIS to determine the rate at which randomly generated territories would include a seismic line simply by chance. This gave us an estimate of the reference condition (how territories would be arranged in a patch of forest without lines). We created a $4 \times 4-\mathrm{km}$ landscape and filled it with either a low density ( $\sim .1 \mathrm{males} / \mathrm{ha})$ or a high density ( 0.5 males/ha) of territories. The high density landscape represented the density we observed in the field in areas where males had four neighbors. Low density was chosen to represent a situation with one-quarter of this density and was typical of what we observed in areas where males had a single neighbor. Territory size was simulated as the mean area of the $100 \%$ minimum convex polygons in our study area. Territory centers where based on random points generated using Hawth's Tools Extension in ArcMap 9.3 (esri 2009). We bisected the landscape with five random seismic lines and repeated the randomization 20 times for each density for a total of 100 line and point combinations. We used the same criteria as for the real territories to decide whether to count 
territories as 0 (excluding the line) or 1 (including the line), and we counted only those territories that were within the same distance from the line $(50 \mathrm{~m})$ as the actual territories in our study area. Territories that were within the minimum distance from the line but had part of another territory between them and the line were excluded from analysis. We used the resulting random rate of line inclusion as the predicted probability of inclusion if birds do not adjust territory placement due to lines. Seismic lines should be deemed regenerated when the random and observed rates of line inclusion are no longer statistically different.

\section{Arthropods}

We sampled arthropods in 2009 to test if the assumption that insect abundance was correlated with leaf-litter depth held true for our study area and if there were differences in the relationship between lines and the forest. We used transects that started on one side of the seismic line perpendicular to the edge, crossed the line, and continued into the forest for $100 \mathrm{~m}$ on the other side. At each transect, three samples were collected across the seismic line (one in the center and one on each side $1 \mathrm{~m}$ from the forest edge). Forest samples were collected at the following distances from the edge: 1, 5, 10, $20,30,40,50,60,80$, and $100 \mathrm{~m}$. At each sampling location we used a $15-\mathrm{cm}$ diameter steel pipe to remove a leaf-litter core down to the mineral soil. We put the leaf litter into a white dishpan and hand-picked the sample for $1.5 \mathrm{~min}$ (J. Ball and H. Lankau, personal communication; VanWilgenburg et al. 2001). We collected and measured all arthropods (to the nearest millimeter) and classified them by order and/or shape. At each sampling location we measured litter depth to the nearest centimeter and recorded ground cover of the core as leaf-litter, moss, or bare dirt. Transects were located in Ovenbird territories so that we were measuring food resources relevant to our study species. We located transects on 15 lines and 27 territories in order to sample a range of forest and line regeneration conditions.

\section{Defense effort}

We evaluated the distribution of singing locations, countersinging locations and time spent singing in each bird's territory to assess whether potential landmarks influenced territory defense effort. We located the center of each $100 \%$ minimum convex polygon and, assuming the territory to be a rough circle centered on this point, divided the area into quarters. One quadrant (side) faced the seismic line adjacent to the territory and the opposite quadrant faced the forest interior. The other two quadrants were parallel to the seismic line. For each quadrant we recorded presence/absence of landmarks (seismic lines and distinct breaks in the canopy located between territories and at least $8-\mathrm{m}$ wide), and presence/absence of a neighbor (Fig. 1).

\section{Vegetation}

We compared species composition, density, and height of vegetation between seismic lines and territory interiors to
Fig. 1. Diagram of territories showing location of vegetation plots, how quadrants are labelled, and a typical territory arragement. Each quadrant corresponds to one side of the territory. Territories were divided into quadrants using the seismic line as a reference, so that they were all oriented the same relative to the line. Seismic lines ranged from 5 to 10 $\mathrm{m}$ in width. Territories were 100 to $150 \mathrm{~m}$ in diameter, although shape varied from circular to elliptical.

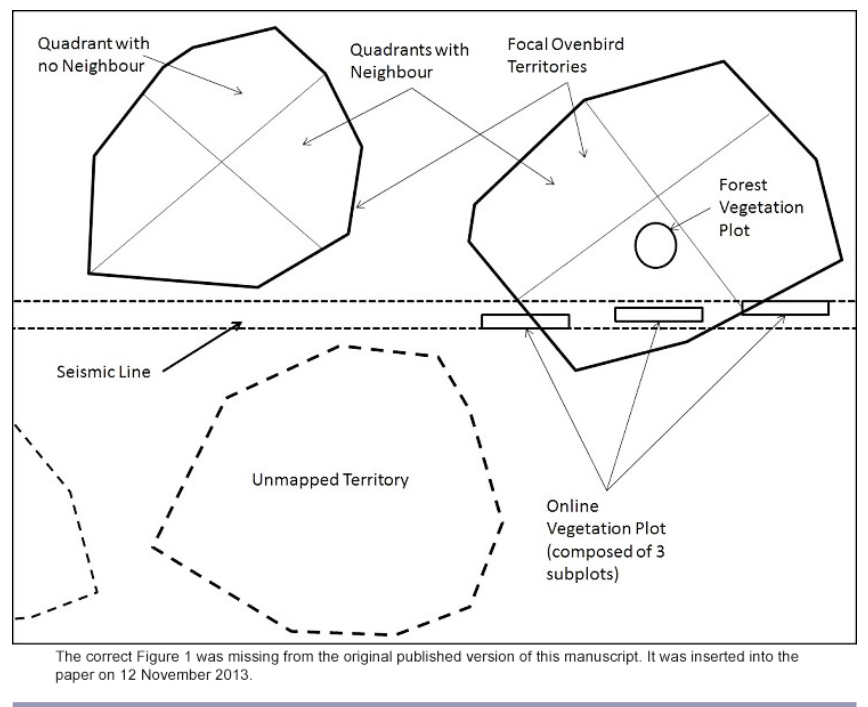

determine if the level of vegetation recovery correlated with the probability an Ovenbird lived across a seismic line. We located one sampling location (online) on the seismic line in the middle section of the line adjacent to the Ovenbird territory. Online vegetation was highly variable, especially on older lines. To account for this, three subplots were placed along a distance of $100 \mathrm{~m}$ to capture the variation in online vegetation. The three subplots were averaged to get the mean online value for each vegetation variable. Online plots were shaped to fit on the seismic line. We located an offline vegetation plot 30 $\mathrm{m}$ into the forest to avoid any vegetation changes related to the seismic line edge (McFarlane 2003). The forest plot was located on the side the Ovenbird used the most. Offline plots covered a maximum area of $0.04 \mathrm{ha}$, and the combination of the three online plots covered a similar area. We measured the density of trees (woody plants $>8 \mathrm{~cm}$ diameter at breast height, DBH) as number of stems/ha and density of shrub stems (defined as woody plants $<8 \mathrm{~cm}$ DBH and $>50 \mathrm{~cm}$ tall) as number of stems $/ \mathrm{m}^{3}$. Ground covered by leaf litter, moss, grass, forbs, and bare ground was visually estimated. Litter depth was measured to the nearest centimeter. We used a clinometer or a graduated $8-\mathrm{m}$ pole (depending on tree height) to measure canopy height on the line and beside the line to compare the regeneration of the line relative to the forest. Canopy height in the forest was recorded as the mode height of the trees to avoid outliers that were particularly tall or short. 
We assessed angular canopy cover using a concave densiometer (Nuttle 1997). Finally, horizontal vegetation density from 0 to $3 \mathrm{~m}$ in height was measured using a $0.5-\mathrm{m}-$ wide coverboard: one observer held the board while the second stood $10 \mathrm{~m}$ away and estimated the percentage of the board that was obscured by green vegetation in four height increments ( 0 to $0.5 \mathrm{~m} ; 0.5$ to $1.0 \mathrm{~m} ; 1.0$ to $2.0 \mathrm{~m}$; and 2.0 to $3.0 \mathrm{~m})$. Further details of our vegetation surveys are available in Bayne et al. (2011).

\section{Statistical analysis}

To test our three hypotheses, we created logistic regression models to evaluate whether the probability of an Ovenbird holding a territory across a seismic line (hereafter probability of inclusion) was one of the following:

(1) A function of food availability as measured by leaf-litter depth and percent cover of bare ground (food hypothesis). Leaf-litter depth was used to represent food availability because arthropod abundance was measured only in 2009 but leaf litter was measured in both 2009 and 2009.

(2) A function of vegetation cover (shrub stem density, online tree density, online canopy height, online canopy cover, and line width (protective cover hypothesis). We also looked at how birds responded to our initial categorization of lines (bare, open, medium, and closed) as assessed in the field.

(3) A function of the number of neighbors (landmark hypothesis). Neighbors was treated as a continuous variable with four values $(1,2,3,4)$ corresponding to the number of neighbors/bird.

(4) A function of a combination of these models.

Our response variable for all models was line inclusion, and we categorized territories as 1 if a male Ovenbird included the line within his territory and 0 if it did not include the line. The model that had the greatest support was determined using Akaike's Information Criteria for small sample size, $\mathrm{AIC}_{\mathrm{c}}$ (Anderson 2008). We discussed only those models that were within $10 \mathrm{AIC}_{\mathrm{c}}$ of the top model (Anderson 2008). $\mathrm{AIC}_{\mathrm{c}}$ weights and evidence ratios were also shown. We argue that the food and protective cover hypotheses are not confounded even though both litter depth and protective cover increase with vegetation recovery because the correlation between these variables was $r=0.43$. Some seismic lines had deeper leaf litter but little-to-no canopy cover while others had tall shrubs and trees and relatively shallow leaf litter.

All other analyses did not use AIC because we did not compare alternate models for food-leaf litter relationships, defense effort, or vegetation differences. We analyzed arthropod abundance using a mixed-effects logistic regression model because of the high number of zeros in the data (cores where no arthropod was detected). The response variable was presence/absence of arthropods and the explanatory variables were litter depth and location (line versus forest). Ovenbird territory was included as a random effect to account for repeated samples taken within each bird's territory. A mixedeffects regression model with a Gaussian error distribution was used to analyze whether defense effort differed between quadrants. The presence/absence of a seismic line or neighbor and their interaction for each quadrant were the categorical predictors. We tested for the interaction because seismic lines should reduce defense cost only if there is a neighbor directly adjacent. We used a one-way ANOVA to test whether individual vegetation variables were different among line categories and territory interiors. A Tukey-HSD post hoc test was used to determine which groups were different from each other. All models were fit in Stata Version 11.1 (StataCorp 2010).

\section{RESULTS}

Field data were collected in 2008 and 2009, and the data were analyzed in 2010. We mapped the territories of 52 colormarked male Ovenbirds, 19 in 2008 and 33 in 2009. Eight were located beside bare lines, 12 near open lines, 17 near medium lines, and 15 near closed lines (Table 1). Seven birds had 1 neighbor, 14 birds had 2 neighbors, 23 birds had 3 neighbors, and 8 birds had 4 neighbors (Table 1). The mean number of singing locations collected for each Ovenbird was $37(\mathrm{SD}=16.7, n=52, \min .=13, \max .=86)$. Mean territory size was 1.07 ha $(\mathrm{SD}=0.69, n=52)$. The mean distance between focal individuals within the same forest patch was 83 $\mathrm{m}(\mathrm{SD}=69 \mathrm{~m}, n=50)$. This did not include patches with single individuals. We did not use data from birds with $<10$ points and/or $<30 \mathrm{~min}$ of observation of singing behavior. We discarded data from 5 individuals where we could not verify that the points from different tracking sessions belonged to the same bird.

Table 1. Conspecific density and line category combinations: summary.

\begin{tabular}{lccccc}
\hline \hline \multirow{2}{*}{$\begin{array}{l}\text { Seismic line } \\
\text { category }\end{array}$} & 1 & 2 & 3 & 4 & Total \\
\cline { 2 - 6 } & 2 & 2 & 2 & 2 & 8 \\
Bare & 0 & 6 & 6 & 1 & 13 \\
Open & 3 & 5 & 7 & 1 & 16 \\
Medium & 2 & 1 & 8 & 4 & 15 \\
Closed & 7 & 14 & 23 & 8 & 52 \\
Total & & & & & \\
& &
\end{tabular}

The three top-ranking models ( $<10 \mathrm{AIC}_{\mathrm{c}}$ different) all included the number of neighbors. The best model for predicting rate of line inclusion by Ovenbirds included the number of neighbors, percent bare ground cover, leaf-litter depth and canopy cover (Table 2). This model was $80 \%$ more likely to 
Table 2. Ranked logistic regression models predicting probability of line inclusion ranked by AICc score. The full sample size of 52 birds was used in all models. Models are identified by hypothesis: $\mathrm{N}=$ neighbors hypothesis; $\mathrm{F}=$ food hypothesis; $\mathrm{P}=$ predation hypothesis. Both hypotheses and models are presented because there are multiple models for each hypothesis as well as combined models. The evidence ratio (ER) shows the support for the top model relative to all other models, while the Akaike weights $(w)$ indicate the probability that a model ranks higher than the lower ranked models.

\begin{tabular}{|c|c|c|c|c|c|c|c|c|}
\hline Hypothesis & Model & $\begin{array}{c}\text { Log } \\
\text { likelihood }\end{array}$ & $\mathrm{k}$ & $\mathrm{AIC}_{\mathrm{c}}$ & $\begin{array}{c}\Delta \\
\mathrm{AIC}_{c} \\
\end{array}$ & $\begin{array}{c}\text { Model } \\
\text { likelihood }\end{array}$ & $w$ & $\begin{array}{c}\text { Evidence } \\
\text { ratio }\end{array}$ \\
\hline NFP & Neighbors + bare ground + canopy cover + litter depth & -21.98 & 5 & 55.26 & 0.00 & 1.00 & 0.80 & 1.00 \\
\hline NF & Neighbors + bare ground + litter depth & -24.67 & 4 & 58.20 & 2.94 & 0.23 & 0.18 & 4.35 \\
\hline NP & Neighbors + canopy cover & -28.63 & 3 & 63.76 & 8.50 & 0.01 & 0.01 & 70.19 \\
\hline $\mathrm{N}$ & Neighbors & -31.65 & 2 & 67.55 & 12.29 & 0.00 & 0.00 & 465.81 \\
\hline $\mathrm{F}$ & Litter depth + bare ground & -30.71 & 3 & 67.91 & 12.65 & 0.00 & 0.00 & 558.84 \\
\hline FP & Bare ground + litter depth + canopy cover & -29.56 & 4 & 67.97 & 12.71 & 0.00 & 0.00 & 574.77 \\
\hline $\mathrm{F}$ & Bare ground & -32.39 & 2 & 69.03 & 13.77 & 0.00 & 0.00 & 977.70 \\
\hline $\mathrm{P}$ & Canopy cover & -32.98 & 2 & 70.21 & 14.95 & 0.00 & 0.00 & $17,66.32$ \\
\hline \multirow[t]{2}{*}{ NP } & Neighbors + line category & -29.69 & 5 & 70.69 & 15.43 & 0.00 & 0.00 & $2,245.72$ \\
\hline & Base & -35.08 & 1 & 72.23 & 16.97 & 0.00 & 0.00 & $4,850.83$ \\
\hline
\end{tabular}

be the top model than any other model (Akaike weight $=0.80$, Table 2). An increase in the percent cover of bare ground made line inclusion 0.86 times less likely, while an increase in canopy cover made line inclusion 1.1 times more likely (Table $3)$. An increase in the number of neighbors reduced the probability that the line would be included in the territory 0.13 times for every additional neighbor (Table 3 ).

Table 3. Parameter estimates and odds ratios for variables in the top-ranked logistic regression model (according to AICc score) in Table 2 . The probability of line inclusion decreases with increasing amount of bare ground, more neighbors, and reduced canopy cover. Asterisks indicate significant trends ( $\alpha$ $=0.05)$. The direction of the response was the same for each explanatory variable in all lower ranked models. Because of the high Akaike weight (0.80), we present only the top model.

\begin{tabular}{lccccc}
\hline \hline & & & & \multicolumn{2}{c}{$\begin{array}{c}\text { Confidence } \\
\text { interval }\end{array}$} \\
\cline { 3 - 6 } $\begin{array}{l}\text { Explanatory } \\
\text { variable }\end{array}$ & $\begin{array}{c}\text { Odds } \\
\text { ratio }\end{array}$ & $\begin{array}{c}\text { Coeffi- } \\
\text { cient }\end{array}$ & SE & $\begin{array}{c}\text { Lower } \\
95 \%\end{array}$ & $\begin{array}{c}\text { Upper } \\
95 \%\end{array}$ \\
\hline Neighbors & 0.130 & $-2.039^{*}$ & 0.612 & -3.238 & -0.84 \\
Bare ground & 0.862 & $-0.149^{*}$ & 0.062 & -0.271 & -0.028 \\
Litter depth & 0.643 & $-0.441^{*}$ & 0.177 & -0.789 & -0.093 \\
Canopy cover & 1.108 & $-0.103^{*}$ & 0.042 & 0.02 & 0.186 \\
Constant & & 11.581 & 3.225 & 5.26 & 17.902 \\
& & & & & \\
\hline
\end{tabular}

An increase in line type, as categorized in the field, increased the probability that Ovenbirds would include lines (Fig. 2). The greatest difference in line regeneration effects was between bare lines and all other lines. Birds next to bare lines consistently included the line 15 to $28 \%$ less than any other category regardless of the number of neighbors (Fig. 2). Open and medium lines were almost identical in their effect on line inclusion. Birds living next to closed lines had the highest rates of line inclusion regardless of the number of neighbors (Fig. 2).

Fig. 2. Probability that territories include lines as a function of the number of neighbors and line category. $95 \%$ confidence intervals (dotted lines) indicate whether the measured value is different from the expected value (straight line). The expected value represents the probability of inclusion if birds placed territories randomly without regard for seismic line location. Based on 100 runs, the expected rate of line inclusion simply due to chance is $65 \%$ $(95 \% \mathrm{CI}=+/-1.2 \%$; SD $=+/-6.1 \%)$.

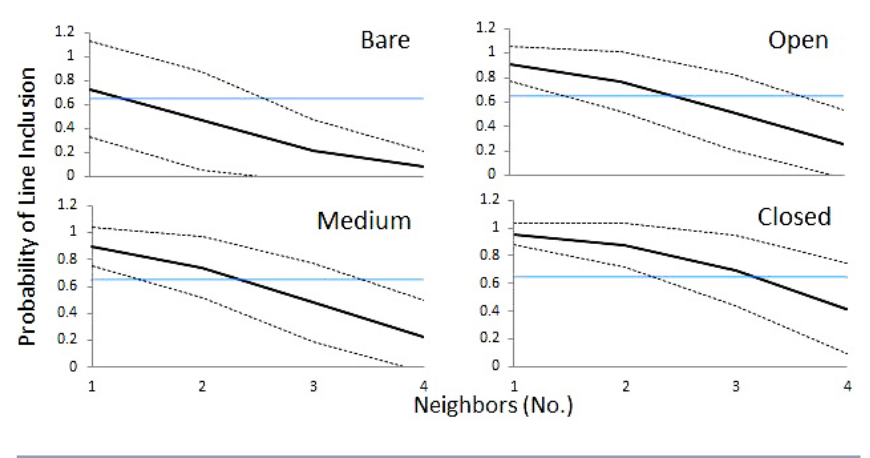

\section{Simulation}

For the simulated high and low density landscapes, $65 \%$ of the territories were predicted to include the hypothetical line by chance. In comparison, birds in our dataset with four neighbors near bare, open, and medium lines included them 
8,26 , and $23 \%$ of the time, which was significantly different than what would have been expected due to chance (Fig. 2). Of the birds with four neighbors, $42 \%$ included the closed line but $95 \%$ confidence intervals included the possibility this result was no different from what the simulation predicted (65\%) (Fig. 2). When Ovenbird density was low (one neighbor), lines in the open, medium, and closed categories were included more frequently than expected $(91,90$, and $96 \%$, respectively).

\section{Arthropods}

The probability of detecting arthropods in seismic line leaflitter samples increased as litter depth increased $(b=0.066$, $\mathrm{SE}=0.016, p<0.001)$, and the likelihood of detecting an arthropod in a sample increased 1.07 times for every additional centimeter of litter depth. The probability of arthropod detection increased at a greater rate with litter depth on seismic lines $(b=0.165$, se $=0.41, p<0.001)$ than in the forest $(b=$ 1.231, $\mathrm{SE}=0.331, p<0.001)$ because of a significant interaction ( $p=0.003$ ) (Fig. 3).

Fig. 3. Probability of detecting arthropods in a $15-\mathrm{cm}$ diameter litter core as a function of litter depth on seismic lines and in the forest.

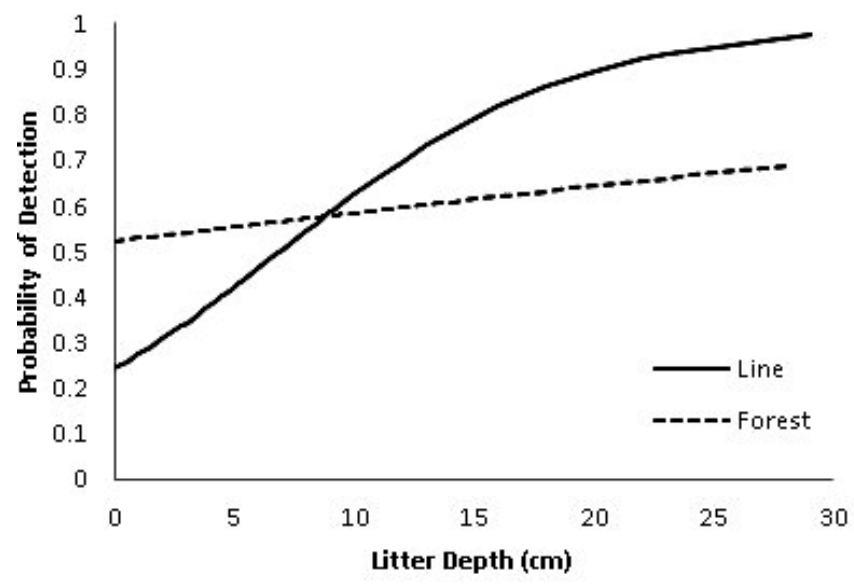

\section{Defense effort}

There was no marked reduction in the proportion of singing locations, countersinging locations, or time spent relative to seismic lines (Table 4). There was also no significant interaction between the location of neighbors and the location of seismic lines. The proportion of countersinging locations was greater on sides that had a neighbor $(b=0.16, \mathrm{SE}=0.043$; $p<0.001)$.

\section{Vegetation comparisons}

Once lines reach the closed category, vegetation characteristics were similar to those in the forest interior except for tree density (237 stems/ha on the lines and 1237 stems/ha in the forest) and canopy height (10 $\mathrm{m}$ on lines and $24 \mathrm{~m}$ in the forest; Table 5). Closed lines differed significantly from territory interiors in tree density and canopy height (Table 5).

Table 4. Mean proportion of singing locations, countersinging locations, and time spent, for all quadrants with and without landmarks and with and without neighbors. Italicized numbers represent standard errors on the mean. Asterisks indicate a significant difference in the means $(\alpha=0.05)$.

\begin{tabular}{lccc}
\hline \hline & & \multicolumn{2}{c}{ Neighbor } \\
\cline { 3 - 4 } Response variable & Landmark & No & Yes \\
\hline Singing locations & No & 0.237 & 0.255 \\
& & 0.015 & 0.018 \\
& Yes & 0.233 & 0.263 \\
Counter singing & & 0.044 & 0.023 \\
locations & No & 0.145 & $0.318^{*}$ \\
& & 0.026 & 0.038 \\
& Yes & 0.201 & $0.299^{*}$ \\
Time & & 0.059 & 0.051 \\
& \multirow{2}{*}{ No } & 0.229 & 0.261 \\
& & 0.018 & 0.023 \\
& \multirow{2}{*}{ Yes } & 0.214 & 0.256 \\
& & 0.055 & 0.031 \\
& & &
\end{tabular}

\section{DISCUSSION}

Our top-ranked model provides evidence that all three hypothesized mechanisms - the use of lines as landmarks, the amount of potential protective cover, and correlates of food abundance-affect the probability of an Ovenbird including a line within their territory. The food abundance hypothesis is supported by the greater difference in line inclusion between bare lines and all other line types. Litter depth is lowest and percentage of bare ground greatest for bare lines, which means that these lines likely had less food for Ovenbirds. Food resources and leaf-litter depth were correlated; and thicker leaf-litter cores were more likely to contain arthropods. This agrees with existing literature showing that leaf-litter depth is important in determining food abundance for Ovenbirds (Burke and Nol 1998). The differential change in arthropod abundance with increasing leaf-litter depth on the lines suggests low leaf-litter depth values on seismic lines might result in less food relative to similar litter depths in the forest (Fig. 3). This could be caused by microclimate conditions on bare and open lines making leaf litter drier and less productive (Remmert 1981, Ferguson 2004) until taller vegetation establishes better cover. The nonsignificant difference in litter depth between closed, medium, and open lines and the forest suggests that food resources have likely recovered on these seismic lines. Although leaf-litter depth and canopy cover were weakly correlated, the model containing leaf litter, canopy cover, and bare ground ranked higher than models with either variable alone. 
Table 5. Description (means and standard errors of the means (SE) of selected vegetation variables by line type. Means of vegetation in the neighboring forest and landmark areas are included for reference. Asterisks indicate values that are significantly different from the forest interior $(\alpha=0.05)$.

\begin{tabular}{|c|c|c|c|c|c|}
\hline \multirow[t]{2}{*}{ Vegetation variable } & \multicolumn{4}{|c|}{ Line category } & \multirow[b]{2}{*}{$\begin{array}{c}\text { Forest } \\
\text { (Mean) } \\
(S E)\end{array}$} \\
\hline & $\begin{array}{c}\text { Bare } \\
\text { (Mean) } \\
(S E)\end{array}$ & $\begin{array}{c}\text { Open } \\
\text { (Mean) } \\
(S E)\end{array}$ & $\begin{array}{c}\text { Medium } \\
\text { (Mean) } \\
(S E)\end{array}$ & $\begin{array}{c}\text { Closed } \\
\text { (Mean) } \\
(S E)\end{array}$ & \\
\hline \multirow[t]{2}{*}{ Bare ground (\%) } & $24.76 \dagger$ & $8.20 \dagger$ & 1.57 & 1.05 & 0.00 \\
\hline & 3.91 & 2.84 & 1.13 & 1.02 & 0.00 \\
\hline \multirow[t]{2}{*}{ Leaf-litter cover $(\%)$} & 49.78 & 53.78 & 60.78 & 78.79 & 77.62 \\
\hline & 8.03 & 7.74 & 7.92 & 6.98 & 2.92 \\
\hline \multirow[t]{2}{*}{ Litter depth $(\mathrm{cm})$} & $2.04 \dagger$ & 6.3 & 7.21 & 7.26 & 8.77 \\
\hline & 0.25 & 0.76 & 0.55 & 0.40 & 0.33 \\
\hline \multirow[t]{2}{*}{ Shrub stem density $\left(\mathrm{m}^{2}\right)$} & $0.19 \dagger$ & 1.07 & 1.91 & 1.35 & 2.03 \\
\hline & 0.05 & 0.21 & 0.31 & 0.22 & 0.18 \\
\hline \multirow[t]{2}{*}{ Tree density (stem/ha) } & $0.00 \dagger$ & $4.36 \dagger$ & $20.76 \dagger$ & $237.05 \dagger$ & 1215 \\
\hline & 0.00 & 3.03 & 14.38 & 54.58 & 75.6 \\
\hline \multirow[t]{2}{*}{ Canopy height (m) } & $0.00 \dagger$ & $1.31 \dagger$ & $3.70 \dagger$ & $10.34 \dagger$ & 23.85 \\
\hline & 0.00 & 0.12 & 0.29 & 0.94 & 0.74 \\
\hline \multirow[t]{2}{*}{ Canopy cover } & $62.16 \dagger$ & $69.27 \dagger$ & 75.98 & 83.26 & 85.56 \\
\hline & 4.52 & 2.40 & 2.15 & 2.44 & 1.62 \\
\hline \multicolumn{6}{|l|}{ Vegetation density } \\
\hline \multirow[t]{2}{*}{0 to $0.5 \mathrm{~m} \dagger$} & $2.89 \dagger$ & $3.99 \dagger$ & 4.29 & 4.19 & 4.17 \\
\hline & 0.18 & 0.19 & 0.13 & 0.16 & 0.12 \\
\hline \multirow[t]{2}{*}{0.5 to $1.0 \mathrm{~m} \dagger$} & $1.58 \dagger$ & $3.16 \dagger$ & 3.40 & 3.18 & 3.62 \\
\hline & 0.18 & 0.22 & 0.16 & 0.19 & 0.14 \\
\hline \multirow[t]{2}{*}{1.0 to $2.0 \mathrm{~m} \dagger$} & $0.79 \dagger$ & $1.57 \dagger$ & 2.62 & 2.62 & 2.84 \\
\hline & 0.23 & 0.16 & 0.25 & 0.18 & 0.12 \\
\hline \multirow[t]{2}{*}{2.0 to $3.0 \mathrm{~m} \dagger$} & $0.85 \dagger$ & $1.45 \dagger$ & 2.28 & 2.58 & 2.72 \\
\hline & 0.26 & 0.15 & 0.21 & 0.24 & 0.12 \\
\hline
\end{tabular}

$\dagger$ Measured using coverboard (maximum height of $3 \mathrm{~m}$ ).

The role of canopy cover in predicting line inclusion supports the hypothesis that lines with less vegetation may also be perceived as riskier habitat because they lack protective cover. Canopy cover values increase with both vegetation density and height above $1 \mathrm{~m}$. Ovenbirds commonly forage on the ground below shrubs and trees (Porneluzi et al. 2011), and we regularly saw females foraging on the ground below singing males. Bare and open lines have little protective cover from aerial predators, such as hawks and falcons, which are known to hunt along forest edges (Smallwood and Bird 2002, Preston and Beane 2009). As lines regrew and reached our medium category, protective cover at ground level was restored, which seems to allow birds to move across and along lines while foraging without being exposed to visual predators. We observed birds singing on closed lines but never on bare, open, or medium lines. Closed lines had trees with a mean height of $10 \mathrm{~m}$ (which is also the mean height at which we recorded Ovenbirds singing) and canopy cover equal to that of the forest interior, suggesting closed lines meet Ovenbird requirements for protective cover.
The importance of local Ovenbird density (number of neighbors) in determining the probability of inclusion partially supports the landmark hypothesis. If a bird has few neighbors, there is less need for birds to agree on territory boundaries, and individuals may roam more widely simply because they can. Alternatively, if a bird has neighbors on more sides, it will have an increased need to defend its territory on more sides and more incentive to reduce defense costs by any means available. Seismic lines are more likely to be the boundary of one side of the territory for most individuals in areas with a high density of conspecifics. On bare, open, and medium lines, lack of food and cover (i.e., quality of the line area) may also contribute to line exclusion because the amount of energy required to defend the area is not compensated by the resources available. We found no support for landmarks reducing defense effort. The greater proportion of countersinging locations on the side of the territory with a neighbor indicates that individuals do focus more effort on the sides of the territory where there is the most threat. One reason we may not have detected a benefit from the presence of landmarks might be that this benefit is most noticeable during territorial 
establishment when more aggressive interactions occur (Lamanna and Eason 2003). Additionally, singing rate and time spent are not exclusively used for territorial defense (Lein 1981). However, the fact that Ovenbirds on opposite sides of the line will both live up to the edge of but not include the line - even on closed lines where the quality of the line area is no longer lower than the forest-does support the landmark hypothesis. We have observed a number of instances where males were countersinging and having altercations from perches on opposite sides of a seismic line. We observed the same behavior at territory edges within the forest interior. Our results suggest that seismic lines act as landmarks, thus adding to the existing literature showing differences in topography and vegetation characteristics at bird territory boundaries (Errington 1930, Reid and Weatherhead 1988, St. Louis et al. 2004).

Although use of landmarks may make delineation of territorial boundaries easier, the overall effect on Ovenbird populations may be negative. Machtans (2006) found that total Ovenbird density declined after seismic lines were cut. Geometric relationships demonstrate that bird density at the local scale is reduced with forest dissection because fewer territories fit into patches of forest bisected by seismic lines in a landscape saturated with birds (Bayne et al. 2005b). Territorial birds tend to have round- to hexagonal-shaped territories because this shape results in the smallest edge to area ratio and potentially minimizes defense costs (Barlow 1974). The wedge- and triangle-shaped pieces of forest created by overlapping seismic lines mean that a bird needs to live over a line or defend an odd-shaped territory with potentially higher defense costs (Barlow 1974) to exist in areas with high seismic line dissection. Because an increase in the number of neighbors increases the rate of line exclusion, the effect of seismic lines is greatest where Ovenbirds are most abundant.

We suggest that any perceived risk to Ovenbirds of using seismic lines for foraging may disappear once woody vegetation regrows to a threshold value of about $2 \mathrm{~m}$ (which can occur in good conditions within $<5$ years after line clearing), and risk for territorial defense activities can be mitigated once line vegetation reaches an average height of $10 \mathrm{~m}$ (which occurs 30 to 40 years after clearing in our study area). Food value is likely restored once leaf-litter depth reaches a mean of 7 to $8 \mathrm{~cm}$. The vegetation characteristics that determine whether lines are suitable as landmarks are most likely tree density and height. These variables are still significantly different between closed lines and territory interiors, suggesting that landmark behavior may persist for a long time. The rate of line inclusion on closed lines is $23 \%$ lower than the predicted value; however, our sample size of birds with four neighbors is small (8), and there is uncertainty, due to the wide confidence intervals, about whether the pattern we observed is different than predicted by our simulations. We conclude that 30-to-40-year old lines are close to being functionally regenerated for Ovenbirds.

The amount of habitat directly lost to seismic lines at the landscape level is relatively low (about 1 to $2 \%$ in highly developed areas of Alberta, Auman et al. 2007). Thus, the impact of seismic lines alone is not likely to endanger Ovenbird populations in the boreal forest. However, seismic lines do need to be considered in calculations of the cumulative effects of all of the other industrial activities occurring in the boreal forest, including agriculture, forestry, roads, and intensive oil and gas development (Schneider 2002). We currently do not know how Ovenbirds and other boreal songbirds will be affected when they lose habitat and the remaining forest is also degraded by linear features. Therefore, it is important to consider what mitigation techniques might reduce the impact of seismic lines. Regeneration of forest cover on seismic lines can likely be improved by reducing human use (Lee and Boutin 2006) and using line-clearing techniques that provide good tree seedling microhabitat and reduce soil compaction (Greene et al. 1999). Based on our results and the work of Bayne et al. (2005b), the best management practices for the energy sector to use to mitigate their impacts on species like the Ovenbird seem to be a reduction in line width to $3 \mathrm{~m}$ and the use of line-clearing practices that increase line canopy cover through rapid regeneration of trees to a minimum of half the height of the surrounding forest.

Responses to this article can be read online at: http://www.ace-eco.org/issues/responses.php/596

\section{Acknowledgments:}

We thank James Campbell, Bryce Hoye, Simon Valdez, Martin Lankau, Emily Hamblen, Jesse Tigner, and Calvin Chueng for assistance in the field and lab. The Acho Dene Koe First Nation granted permission to access their traditional lands and provided in-kind support at our field site. Research funding and support were provided by Environmental Studies Research Fund; Environment Canada; Paramount Resources; Alberta Upstream Petroleum Research Fund; Canadian Circumpolar Institute; Alberta Sports, Recreation, Parks and Wilderness Foundation; Association of Field Ornithologists; and Aboriginal Affairs and Northern Development Canada. Inkind support came from the Northwest Territories' Department of Environment and Natural Resources. We would like to thank the following for all their ideas and insight: Karen Halwas, Ray Case, Chandra Venables, Karin Clark, Craig Machtans, Tom Lakusta, David Kerr, and Nicole McCutchen. Personal 
funding to H. L. was provided by the Natural Sciences and Engineering Research Council of Canada (NSERC) and Alberta Advanced Education.

\section{LITERATURE CITED}

Anderson, D. R. 2008. Model based inference in the life sciences: a primer on evidence. Springer, New York, USA. http://dx.doi.org/10.1007/978-0-387-74075-1

Aumann, C., D. R. Farr, and S. Boutin. 2007. Multiple use, overlapping tenures, and the challenge of sustainable forestry in Alberta. The Forestry Chronicle 83:642-650.

Barg, J. J., J. Jones, and R. J. Robertson. 2004. Describing breeding territories of migratory passerines: suggestions for sampling, choice of estimator, and delineation of core areas. Journal of Animal Ecology 74:139-149. http://dx.doi. org/10.1111/j.1365-2656.2004.00906.x

Barlow, G. W. 1974. Hexagonal territories. Animal Behavior 22:876-878. http://dx.doi.org/10.1016/0003-3472(74)90010-4

Bayne, E. M., S. Boutin, B. Tracz, and K. Charest. $2005 a$. Functional and numerical responses of Ovenbirds (Seiurus aurocapilla) to changing seismic exploration practices in Alberta's boreal forest. Ecoscience 12:216-222.

Bayne, Dr. E., H. Lankau, and J. Tigner. 2011. Ecologicallybased criteria to assess the impact and recovery of seismic lines: the importance of width, regeneration, and seismic density. Environmental Studies Research Funds Report No. 192. Natural Resources Canada and Aboriginal Affairs and Northern Development Canada, Edmonton, Alberta, Canada.

Bayne, E. M., S. L. VanWilgenburg, S. Boutin, and K. A. Hobson. 2005b. Modeling and field-testing of Ovenbird (Seiurus aurocapillus) responses to boreal forest dissection by energy sector development at multiple spatial scales. Landscape Ecology 20:203-216.

Burke, D. M., and E. Nol. 1998. Influence of food abundance, nest site habitat, and forest fragmentation on breeding Ovenbirds. The Auk 115: 96-104. http://dx.doi.org/10.2307/4089115

Dehcho Land Use Planning Committee. 2006. Respect for the land: Dehcho Land Use Plan. Final Draft Plan, May 2006. Fort Providence, Northwest Territories, Canada

Eason, P. K., G. A. Cobs, and K. G. Trinca. 1999. The use of landmarks to define territorial boundaries. Animal Behaviour 58:85-91. http://dx.doi.org/10.1006/anbe.1999.1133

Eggers, S., M. Griesser, and J. Ekman. 2008. Predator-induced reductions in nest visitation rates are modified by forest cover and food availability. Behavioral Ecology 19:1056-1062. http://dx.doi.org/10.1093/beheco/arn063

Environment Canada. 2011. Recovery strategy for the Woodland Caribou (Rangifer tarandus caribou), boreal population in Canada. Species at Risk Act Recovery Strategy Series. Ottawa, Ontario, Canada.

Errington, P. L. 1930. Territory disputes of three nesting marsh hawks. The Wilson Bulletin 42:237-239.

esri. 2009. ArcGIS for Desktop 9.3.1. Redlands, California, USA.

Ferguson, S. H. 2004. Does predation or moisture explain distance to edge distribution of soil arthropods? American Midland Naturalist 152:75-87.

Greene, D. F., J. C. Zasada, L. Sirios, D. Kneeshaw, H. Morin, I. Charron, M.-J. Simard. 1999. A review of the regeneration dynamics of North American boreal forest tree species. Canadian Journal of Forest Research 29:824-839

Haskell, D. G. 2000. Effects of forest roads on macroinvertebrate soil fauna of the southern Appalachian Mountains. Conservation Biology 14:57-63. http://dx.doi. org/10.1046/j.1523-1739.2000.99232.x

Hunter, M. L. 1999. Maintaining biodiversity in forest ecosystems. Cambridge University Press, Cambridge, UK. http://dx.doi.org/10.1017/CBO9780511613029

Kennett, S. 2006. From science-based thresholds to regulatory limits: implementation issues for cumulative effects management. Northern Division, Environment Canada, Yellowknife, Northwest Territories, Canada.

Lamanna, J. R., and P. K. Eason. 2003. Effects of landmarks on territorial establishment. Animal Behaviour 65:471-478. http://dx.doi.org/10.1006/anbe.2003.2095

Latham, A. D. M., M. C. Latham, M. S. Boyce, and S. Boutin. 2011. Movement responses by wolves to industrial linear features and their effect on woodland caribou in northeastern Alberta. Ecological Applications 21:2854-2865. http://dx. doi.org/10.1890/11-0666.1

Lee, P., and S. Boutin. 2006. Persistent and developmental transition of wide seismic lines in the western boreal plains of Canada. Journal of Environmental Management 78:240-250. http://dx.doi.org/10.1016/j.jenvman.2005.03.016

Lein, M. R. 1981. Display behaviour of Ovenbirds (Seiurus aurocapillus) II. Song variation and singing behaviour. The Wilson Bulletin 93:21-41.

Lindenmayer, D. B., C. R. Margules, and D. B. Botkin. 2000. Indicators of biodiversity for ecologically sustainable forest management. Conservation Biology 14: 941-950. http://dx. doi.org/10.1046/j.1523-1739.2000.98533.x

MacFarlane, A. K. 2003. Vegetation response to seismic lines: edge effects and on-line succession. Master's Thesis, Department of Biological Sciences, University of Alberta, Edmonton, Alberta, Canada. 
Machtans, C. S. 2006. Songbird response to seismic lines in the western boreal forest: a manipulative experiment. Canadian Journal of Zoology 84:1421-1430. http://dx.doi. org/10.1139/z06-134

Mesterton-Gibons, M., and E. S. Adams. 2003. Landmarks in territory partitioning: a strategically stable convention? The American Naturalist 161:685-697.

Nuttle, T. 1997. Densiometer bias? Are we measuring the forest or the trees? Wildlife Society Bulletin 25:610-611.

Ortega, Y. K., and D. E. Capen. 1999. Effects of forest roads on habitat quality for Ovenbirds in a forested landscape. The Auk 116:937-946. http://dx.doi.org/10.2307/4089673

Porneluzi, P., M. A. Van Horn, and T. M. Donovan. 2011. Ovenbird (Seiurus aurocapilla). In A. Poole, editor. The birds of North America online. Cornell Lab of Ornithology, Ithaca, New York, USA. [online] URL: http://bna.birds.cornell.edu/ bna/species/256.

Preston, C. R., and R. D. Beane. 2009. Red-tailed Hawk (Buteo jamaicensis). In A. Poole, editor. The birds of North America online. Cornell Lab of Ornithology, Ithaca, New York, USA. [online] URL: http://bna.birds.cornell.edu/bna/species/052. http://dx.doi.org/10.2173/bna.52

Reid, M. L., and P. J. Weatherhead. 1988. Topographical constraints on competition for territories. Oikos 51: 115-117. http://dx.doi.org/10.2307/3565819

Remmert, H. 1981. Body size of terrestrial arthropods and biomass of their populations in relation to the abiotic parameters of their milieu. Oecologia 50:12-13. http://dx.doi. org/10.1007/BF00378789

Rodriguez, A., H. Adren, and G. Jansson. 2001 Habitatmediated predation risk and decision making of small birds at forest edges. Oikos 95:383-396

Schneider, R. R. 2002. Alternative futures: Alberta's boreal forest at the crossroads. Alberta Centre for Boreal Research and the Federation of Alberta Naturalists, Edmonton, Alberta, Canada.

Smallwood, John A., and David M. Bird. 2002. American Kestrel (Falco sparverius). In A. Poole, editor. The birds of North America online. Cornell Lab of Ornithology, Ithaca, New York, USA. [online] URL: http://bna.birds.cornell.edu/ bna/species/602. http://dx.doi.org/10.2173/bna.602

Smith, T. M., and H. H. Shugart. 1987. Territory size variation in the Ovenbird: the role of habitat structure. Ecology 68:695-704. http://dx.doi.org/10.2307/1938475

StataCorp. 2010. Stata Version 11.1. College Station, Texas, USA.
St. Louis, V., M. Forten, and A. Desrochers. 2004. Spatial association between forest heterogeneity and breeding territory boundaries of two forest songbirds. Landscape Ecology 19:591-601. http://dx.doi.org/10.1023/B:

\section{LAND.0000042849.63040.a9}

Tigner, D. J. 2012. Measuring wildlife response to seismic lines to inform land use planning decisions in northwest Canada. Dissertation, University of Alberta, Edmonton, Alberta, Canada.

VanWilgenburg, S. L., D. F. Mazerolle, and K. A. Hobson. 2001. Patterns of arthropod abundance, vegetation, and microclimate at boreal forest edge and interior in two landscapes: implications for forest birds. Ecoscience 8:454-461.

Walther, B. A., and A. G. Gosler. 2001. The effects of food availability and distance to protective cover on the winter foraging behaviour of tits (Aves: Parus). Oecologia 129:312-320. http://dx.doi.org/10.1007/s004420100713 